\title{
Technical advancements in robotic prostatectomy: single-port extraperitoneal robotic-assisted radical prostatectomy and single-port transperineal robotic-assisted radical prostatectomy
}

\author{
Alireza Aminsharifi ${ }^{1,2}$, Guilherme Sawczyn ${ }^{1}$, Clark A. Wilson ${ }^{1}$, Juan Garisto ${ }^{1}$, Jihad Kaouk ${ }^{1}$ \\ ${ }^{1}$ Glickman Urological and Kidney Institute, Cleveland Clinic, Cleveland, OH, USA; ${ }^{2}$ Department of Urology, Shiraz University of Medical Sciences, \\ Shiraz, Iran \\ Contributions: (I) Conception and design: J Kaouk, A Aminsharifi, G Sawczyn; (II) Administrative support: J Kaouk, G Sawczyn; (III) Provision of \\ study materials or patients: J Kaouk, J Garisto, CA Wilson; (IV) Collection and assembly of data: G Sawczyn, J Garisto, CA Wilson; (V) Data analysis \\ and interpretation: J Kaouk, A Aminsharifi, G Sawczyn; (VI) Manuscript writing: All authors; (VII) Final approval of manuscript: All authors. \\ Correspondence to: Jihad Kaouk, MD. Zegarac-Pollock Professor of Surgery Director, Center for Laparoscopic and Robotic Surgery Institute Vice \\ Chair for Surgical Innovations, Glickman Urological and Kidney Institute, Cleveland Clinic, 9500 Euclid Ave, Q-10 Cleveland, OH 44195, USA. \\ Email: kaoukj@ccf.org.
}

Background: To describe our step-by-step techniques for single-port robotic-assisted extraperitoneal and perineal radical prostatectomy as recent technical advancements in this field.

Methods: An English-language literature review was done using search terms including extraperitoneal, transperineal, single-port, robotic surgery, prostate cancer, radical prostatectomy in various combinations. Unique features of the da Vinci $\mathrm{SP}^{\circledR}$ platform are discussed. Details of surgical techniques with single-port robotic platform are also covered.

Results: The relatively recent introduction of the da Vinci SP platform has led to the development of novel techniques for radical prostatectomy. Unique features of this platform including intracorporeal triangulation and double-articulating instruments will likely lead to widespread applications of this novel system. The principles of radical prostatectomy are reproducible with both extraperitoneal and perineal approaches via a single incision.

Conclusions: A better cosmetic results as well as a quick recovery maybe potential advantages of singleport extraperitoneal/transperineal robotic prostatectomy. By avoiding the peritoneal cavity, a lower rate of bowel related complications and minimum systemic $\mathrm{CO}_{2}$ absorption can be expected. Adverse effects of steep Trendelenburg positioning can be avoided with these techniques. Evaluation of the oncological and functional outcomes of these techniques will be necessary. Comparative trials with standard robotic surgery and cost-analysis studies remain hot topics for research after implementation of these new platforms at any institute.

Keywords: Single-port radical prostatectomy; extraperitoneal prostatectomy; perineal prostatectomy; robotic surgery; prostate cancer

Submitted Sep 03, 2019. Accepted for publication Nov 18, 2019.

doi: $10.21037 /$ tau.2019.11.35

View this article at: http://dx.doi.org/10.21037/tau.2019.11.35 


\section{Introduction}

In the current era, robotic radical prostatectomy has been popularized as a standard minimally invasive procedure for the treatment of organ confined prostate cancer. In addition to the standard anterior transperitoneal approach, several alternative approaches such as posterior transperitoneal (Retzius sparing), extraperitoneal, transvesical, and transperineal have been described (1).

To further minimize the surgical morbidity of radical prostatectomy, the concept of single site surgery has been proposed. While the cosmetic benefits of laparoendoscopic single site surgery (LESS) have been shown in several studies, a number of obstacles such as limited objective data on improved postoperative morbidity and ergonomic challenges with LESS preclude its widespread application. Notably many institutions have not implemented LESS due to its inherent technical difficulties (2-4).

With the recent advent and clinical application of the da Vinci SP ${ }^{\circledR}$ (Intuitive Surgical, Sunnyvale, CA, USA) as a "purpose-designed" single-port robotic platform, our group has reported outcomes of single site robotic prostatectomy using this platform (5-8). The concept of "I"-(on entry) and "Y"-(inside the body) configurations of the robotic instruments follows the triangulation principle. The intracorporeal triangulation minimizes arm collision during surgery and provides adequate working space (9). This system addresses the main disadvantages of LESS including lack of triangulation and a limited range of motion.

In this article, we describe the technical details of extraperitoneal single-port robotic radical prostatectomy and single-port transperineal robotic radical prostatectomy. As emerging techniques in this field, both approaches can potentially offer a less morbid surgical procedure with a rapid convalescence period.

\section{Methods}

A literature search was conducted in order to review the relevant publications regarding the application of new robotic platforms for single site prostatectomy. After excluding duplicated articles, peer reviewed articles relevant to extraperitoneal and transperineal singleport robotic prostatectomy in English-language were considered, retrieved and reviewed. Publications were sourced using PubMed ${ }^{\circledR}$ and Web of ScienceTM databases. Terms included for this search were (extraperitoneal) (transperineal) (single-port) (robotic surgery) with (prostate cancer, radical prostatectomy) in various combinations.

\section{Results}

After clinical application of the da Vinci SP platform, in late 2018, novel techniques for radical prostatectomy has been introduced. Unique features of the SP platform including intracorporeal triangulation and doublearticulating instruments will likely lead to widespread applications of this novel system. The principles of radical prostatectomy are reproducible with both extraperitoneal and perineal approaches via a single incision.

\section{Unique features of the da Vinci $S P^{\circledR}$ surgical platform}

The da Vinci SP platform has several unique and novel features (10): this platform has (I) a single robotic arm docked to a $25 \mathrm{~mm}$ multichannel port (Figure 1A,B,C); (II) a $12 \times 10 \mathrm{~mm}$ articulating camera and three $6 \mathrm{~mm}$ articulating instruments. All instruments and the camera have a double articulating design (i.e., wrist and elbow). Therefore, after all instruments are passed through the port in the "I"-(i.e., straight) configuration, they can be reconfigured to a "Y"(i.e., triangle) shape to provide intracorporeal triangulation (Figure 1D,E); (III) a virtual guidance system allows the surgeon to visualize the spatial relations of each arm and the camera during surgery (Figure 1D,E); (IV) an extra-clutch by which the surgeon can move the camera and working arms independently or as a single unit during surgery (Figure 1F) (10).

\section{Single-port extraperitoneal robotic radical prostatectomy}

With this procedure, radical prostatectomy can be accomplished via a small $2-3 \mathrm{~cm}$ infraumbilical incision with no additional ports. Additionally, the extraperitoneal approach may be associated with a lower incidence of postoperative ileus and therefore a shorter hospital stay and quicker recovery (11). Since surgery is performed in supine position, unlike classic robotic prostatectomy, adverse effects associated with Trendelenburg positioning including ventilation difficulty, increases in intraocular, intracranial and intrathoracic pressures can be avoided (12).

\section{Patient selection}

At least in initial experience, the authors recommend excluding patients with previous history of abdominal surgery with incisions extending below the umbilicus (due to difficulty in developing Retzius space), large prostate glands (>100 grms), morbid obesity, prior prostate surgery and prostate cancer with high risk features (12). 

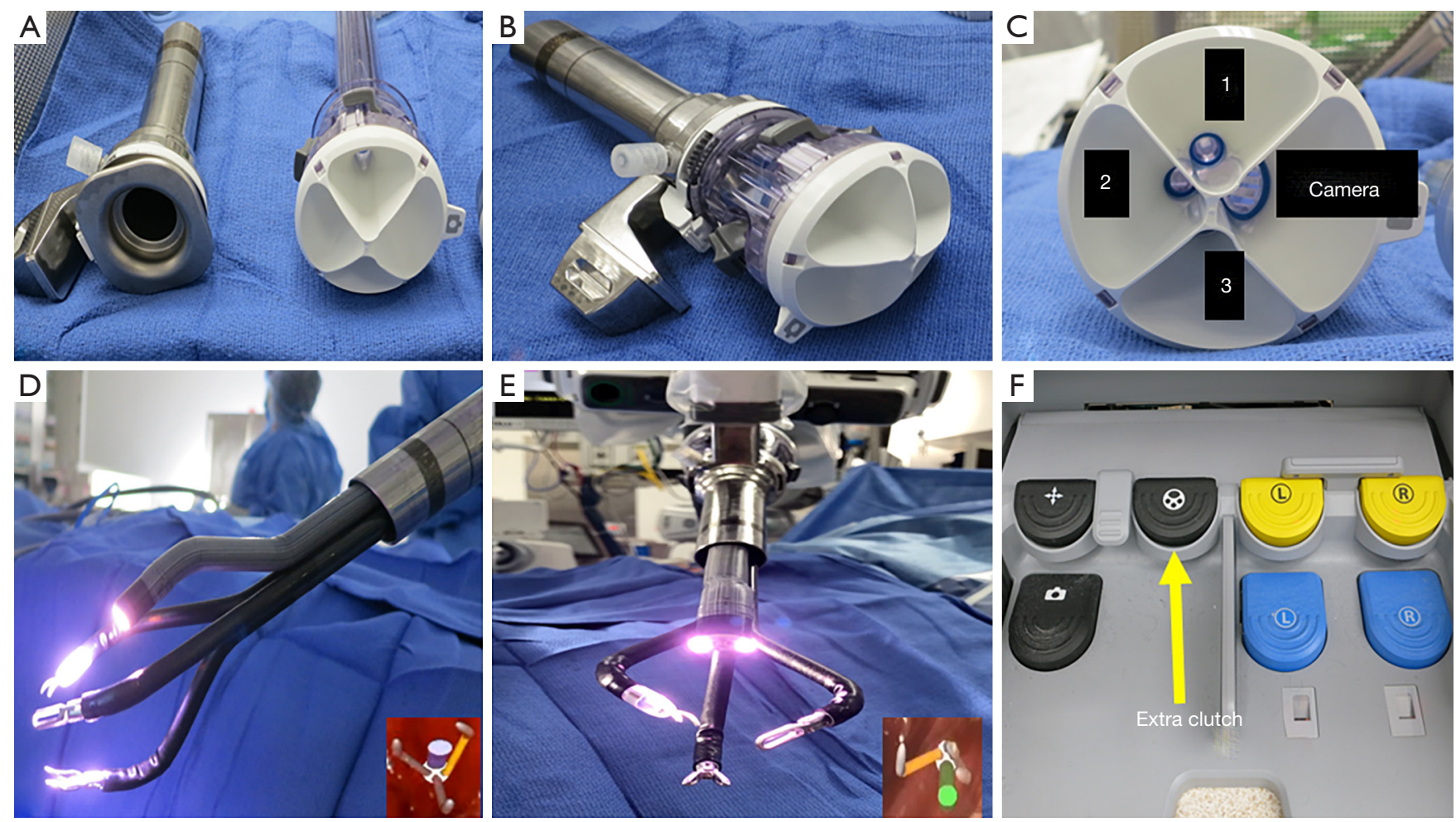

Figure 1 The da Vinci $\mathrm{SP}^{\circledR}$ platform has some unique features making the single-port surgery easier: a 25 mm multichannel port (A,B,C) accommodates a $12 \times 10 \mathrm{~mm}$ articulating camera and three $6 \mathrm{~mm}$ articulating instruments. All instruments and the camera have a double articulating design making intracoporeal triangulation possible $(\mathrm{D}, \mathrm{E})$; the virtual guidance system allowing the surgeon to conceptualize the spatial relation of each arm and camera during surgery (D,E-insets); (F) the extra-clutch at surgeon's console helps to move the camera and working arms as a single unit or independently during different steps of surgery.

The procedure is done under general anesthesia in supine position. Prophylactic single dose intravenous antibiotic and prophylactic subcutaneous heparin are administrated prior to incision.

\section{Access}

As a rule of thumb, the docking point should be at least $15 \mathrm{~cm}$ away from the target anatomy (i.e., prostate) for adequate range of motion. A $2-3 \mathrm{~cm}$ infraumbilical incision is made about one fingerbreadth below the umbilicus. The anterior rectus sheath is identified and incised sharply. After developing the space of Retzius, the SPACEMAKER ${ }^{\mathrm{TM}}$ (Covidien, Dublin, Ireland) surgical balloon dissector system is placed through the incision and placed under the pubic bone. Adequate working space is then developed by inflating the balloon with $400 \mathrm{cc}$ of air (Figure 2A,B).

\section{Port placement}

The wound retractor/protector component (Alexis ${ }^{\circledR}$ ) of the GelPOINT system (Applied Medical, Rancho Santa Margarita, CA, USA) is fixed to the wound. The inner ring is secured under the rectus fascia and the outer ring is kept over the skin to provide $360^{\circ}$ of atraumatic wound retraction. The $25 \mathrm{~mm} \mathrm{SP}^{\circledR}$ cannula with a multichannel guide port as well as a $12 \mathrm{~mm}$ laparoscopic port are inserted into the GelSeal cap (Figure 2C,D). Then the GelSeal cap is attached to the wound retractor, insufflation is established and the $\mathrm{SP}^{\circledR}$ robot is docked to the multichannel port (Figure 2D,E,F).

\section{Floating technique}

Unlike conventional LESS surgery, the Alexis ${ }^{\circledR}$ wound retractor is not fixed to the skin. Instead, the Alexis ${ }^{\circledR}$ acts as a conduit between the robotic arm and patient body. The GelPOINT system is placed in a "floating" fashion during surgery and the robotic cannula is above the patient's body. This allows for maximal working space of the robotic instruments (Figure 2F). 

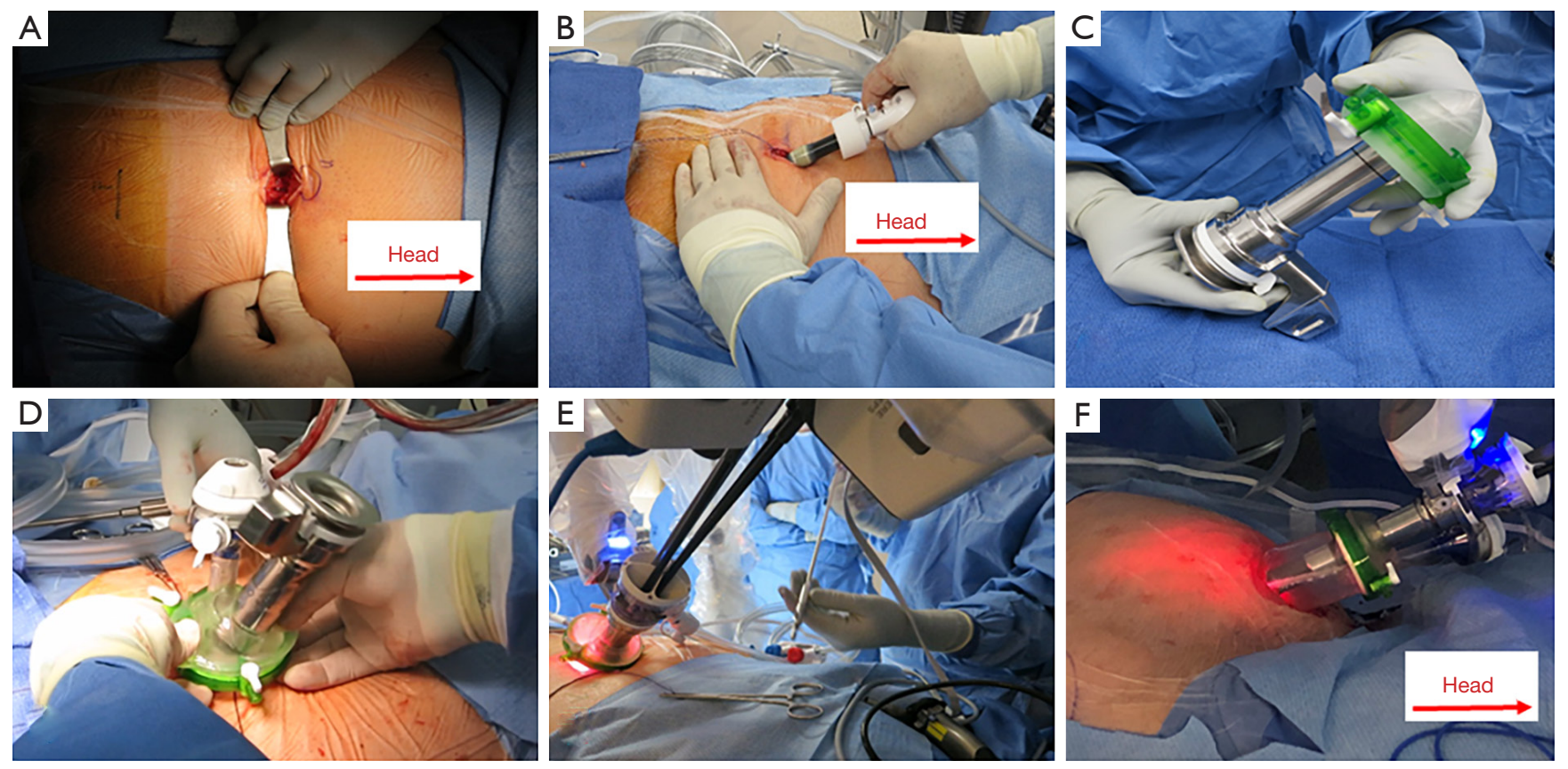

Figure 2 Access for single-port extraperitoneal robotic radical prostatectomy: $(A, B)$ a $2-3 \mathrm{~cm}$ infraumbilical incision is made below the umbilicus. After incising the anterior rectus sheath, the preperitoneal space is developed and the balloon dissector system is introduced in the Retzius space under the pubic bone. Adequate work space in retropubic area is developed by inflating the balloon; (C,D) the wound retractor/protector component (Alexis ${ }^{\circledR}$ ) of the GelPOINT system (Applied Medical, Rancho Santa Margarita, CA, USA) is fixed to the wound and $(\mathrm{C}, \mathrm{D}, \mathrm{E})$ a $25 \mathrm{~mm} \mathrm{SP}{ }^{\circledR}$ cannula with a multichannel guide port as well as a $12 \mathrm{~mm}$ laparoscopic port are inserted into the GelSeal cap (green model) and is fixed to the Alexis ${ }^{\circledR}$; (E,F) floating technique: the Alexis ${ }^{\circledR}$ wound retractor should not be completely fixed to the skin. The GelPOINT system is "floating" during surgery, therefore, the depth, work space and flexibility of the instruments are increased.

\section{Robotic prostatectomy}

After docking, the procedure can be followed step by step according to the standard anterior dissection technique (8). After defatting the prostate, the endopelvic fascia is exposed and incised bilaterally. The dorsal vein complex (DVC) is ligated (Figure $3 A$ ). Following division of the anterior and posterior aspects of the bladder neck (BN) (Figure 3B,C), both vasa and seminal vesicles (SVs) are exposed and dissected (Figure 3D,E). After controlling the prostate pedicles with Hem-o-lok clips (Weck Closure Systems, Research Triangle Park, NC, USA), they are divided (Figure $3 F$ ). The posterior surface of the prostate is then dissected from the rectum. The DVC is divided, the apical dissection is completed and then the urethra is divided sharply (Figure 3G) and the prostate is completely detached. Standard bilateral pelvic lymph node dissection can be done based on the prostate cancer risk category. Finally, the urethrovesical anastomosis is completed with running suture over an 18 Fr catheter (Figure 3H). Water-tightness of the anastomosis is ensured, all specimens are retrieved and the abdominal wall is closed in layers. Figure $3 I$ shows critical structures after completion of pelvic lymph node dissection.

\section{Single-port transperineal robotic-assisted radical prostatectomy}

The technique of radical perineal prostatectomy was first described in 1905 by Young and has undergone multiple technical modifications. Despite its longstanding history, perineal prostatectomy has not been widely adopted in the urology community $(13,14)$. Poor exposure, narrow, deep operative field and problems with learning curve are among obstacles for its popularization.

Kaouk et al. reported the initial series of robotic-assisted perineal radical prostatectomy with multiport and singleport configurations $(15,16)$. We believe that robotic-assisted perineal approach may be a reasonable alternative for radical prostatectomy in patients with challenging abdominal anatomy (i.e., multiple previous abdominal surgeries, kidney 

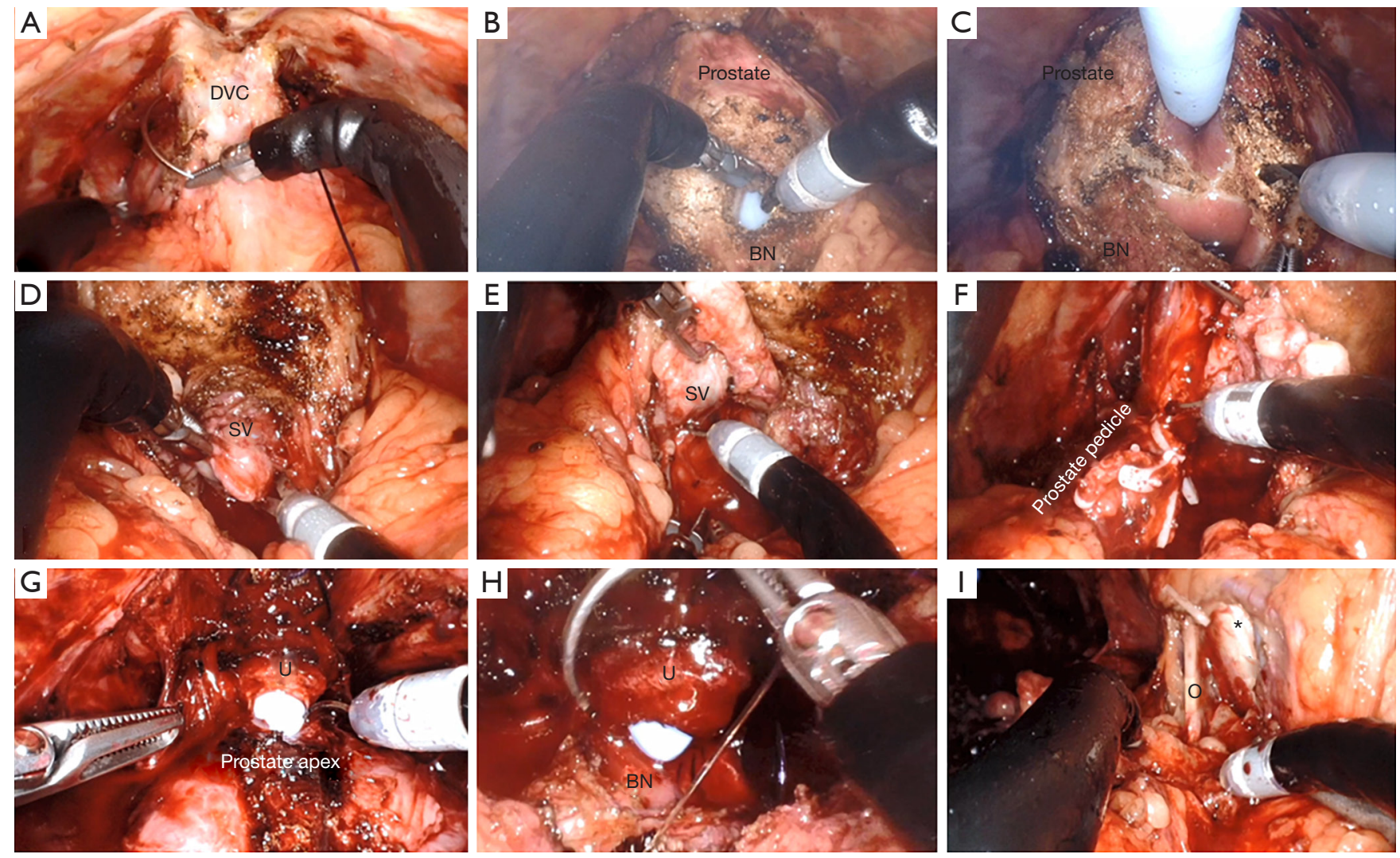

Figure 3 Critical steps during extraperitoneal robotic radical prostatectomy: (A) suture ligation of the DVC; (B,C) sharp division of the anterior and posterior aspects of the $\mathrm{BN}$ for $(\mathrm{D}, \mathrm{E})$ exposure and dissection of both vasa and SVs; (F) after controlling and division of the prostate pedicles, posterior surface of the prostate is then bluntly dissected from the rectum; (G) apical dissection is completed by sharp incision and division of DVC and the urethra $(\mathrm{U}) ;(\mathrm{H})$ urethrovesical anastomosis is accomplished with running stitches; (I) after standard bilateral pelvic lymph node dissection, both obturator nerve $(\mathrm{O})$ and iliac vessels $\left.{ }^{*}\right)$ are well visualized. DVC, dorsal vein complex; BN, bladder neck; SV, seminal vesicle.

transplantation, morbid obesity and patients with intestinal stoma).

The unique features of the da Vinci $\mathrm{SP}^{\circledR}$ platform such as its master-slave design and double articulating instruments with intracorporeal triangulation ability, minimize instrument collision during dissection of prostate through perineal approach (17).

\section{Positioning, perineal access and port placement}

The patient is placed in dorsal lithotomy position with 15-degrees of Trendelenburg. A $2-3 \mathrm{~cm}$ semicircular incision is made between ischial tuberosities and the central tendon of perineal body is divided. The bulbospongiosus and rectourethralis muscles are divided and retracted. The membranous urethra and prostate apex are then be exposed. The inner ring of the Alexis ${ }^{\circledR}$ device (Applied Medical,
Rancho Santa Margarita, CA, USA) is then placed into the wound and sutured in place. $\mathrm{CO}_{2}$ insufflation is maintained at $12-15 \mathrm{mmHg}$ (Figure $4 A$ ). The robot is then docked using a "floating" technique as described above.

\section{Robotic perineal radical prostatectomy}

Prostate dissection is generally started posterolaterally to expose the levator ani muscle fibers on both sides of the prostate laterally and the perirectal fat posteriorly. With this dissection, the posterior surface of the prostate can be easily delineated and released from the rectum (Figure 4B). Dissection is continued in a cephalad direction to open Denonvilliers' fascia. The vasa deferential and SVs are dissected and the vasa are divided (Figure 4B). After ligation of prostate pedicles on both sides, the membranous urethra is sharply divided from the prostate apex to expose the 
A
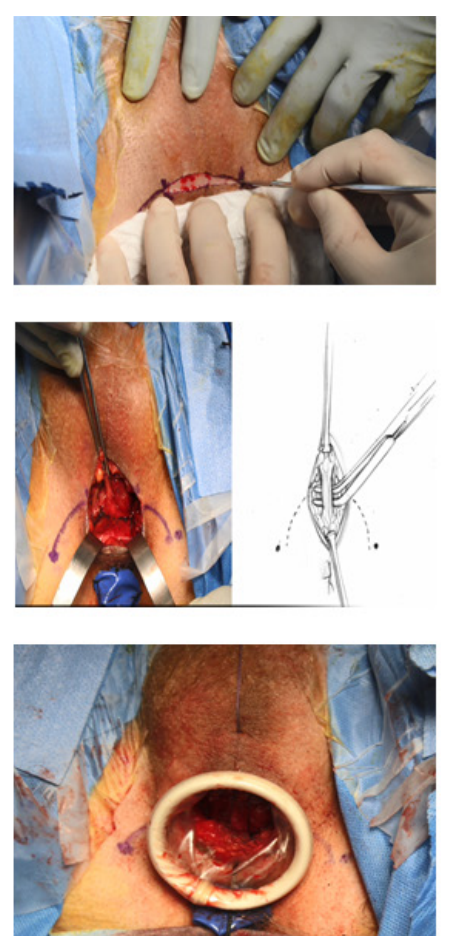

B
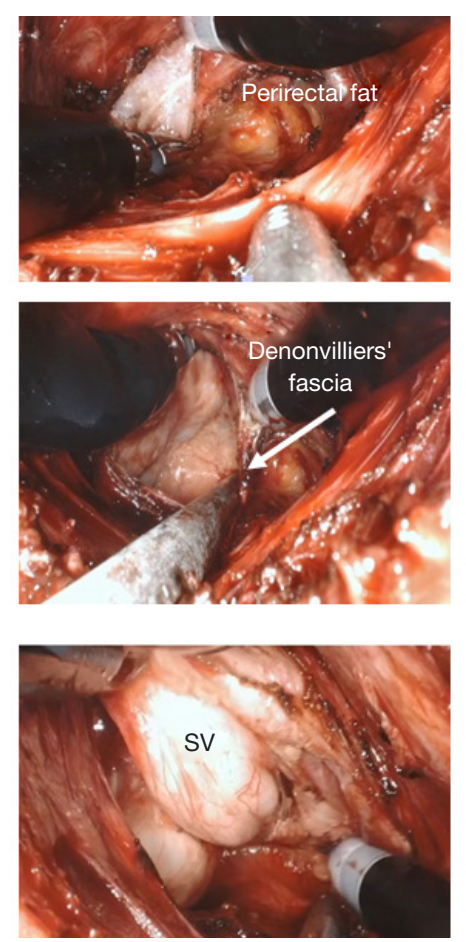

C
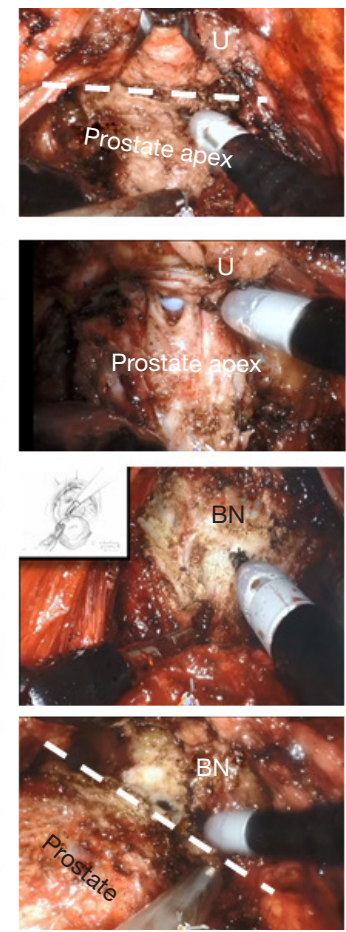

D
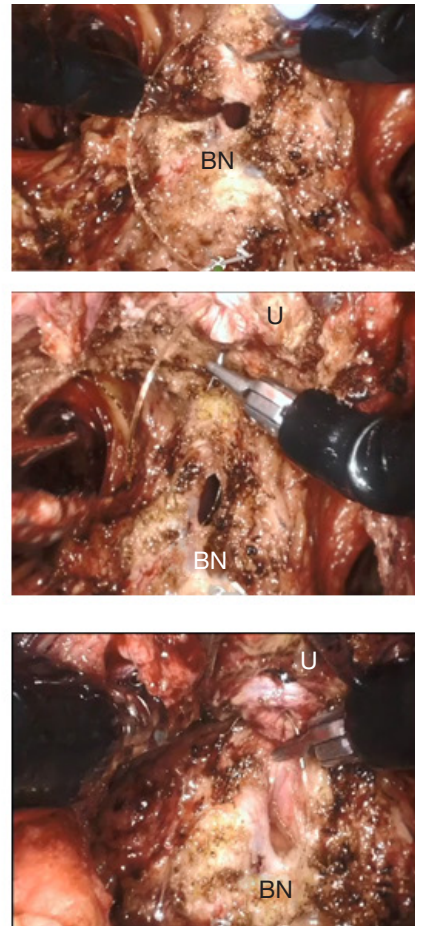

Figure 4 Single-port transperineal robotic-assisted radical prostatectomy. (A) Perineal dissection, access and port placement: a 2-3 cm semicircular incision is made between ischial tuberosities and with blunt and sharp dissections, the central tendon of perineal body, bulbospongiosus and rectourethralis muscles is divided and retracted to apply the GelPOINT system; (B) posterior dissection: dissection in a plane between the prostate and rectum is carried out to expose the perirectal fat posteriorly. After opening the Denonvilliers' fascia, the SVs and vasa can be exposed and released. Both vasa and prostate pedicle are ligated and divided; (C) apical and BN dissection: the membranous urethra $(\mathrm{U})$ is sharply divided from the prostate apex to expose the Foley catheter. The catheter balloon helps to identify the junction between the $\mathrm{BN}$ and prostate. The prostate is then separated from the BN circumferentially; (D) vesicourethral anastomosis: two 3/0 V-Loc ${ }^{\mathrm{TM}}$ (Covidien, Mansfield, MA, USA) sutures can be used. Running sutures start anteriorly at 12 o'clock on the BN from outside to inside, then from inside to outside to the urethra $(\mathrm{U})$. On either side, the anastomosis is completed by approximating the rectal side of the BN and $\mathrm{U}$. $\mathrm{SV}$, seminal vesicle; BN, bladder neck.

Foley catheter (Figure 4C). The catheter balloon helps to identify the junction between the $\mathrm{BN}$ and prostate. Once the anterior and posterior $\mathrm{BN}$ attachments are divided from the prostate (Figure $4 C$ ) the robot is undocked and the specimen is retrieved.

\section{Pelvic lymph node dissection}

The robotic system is redocked and if necessary, the pelvic cavity can be accessed for pelvic lymph node dissection before vesicourethral anastomosis. The lateral perivesical space can be entered by medial retraction of the bladder. Since dissection proceeds in a caudal to cranial direction unlike conventional robotic prostatectomy, the most inferior and lateral aspect of obturator nerve will be visualized at the beginning of the dissection. Additional structures in the obturator fossa (i.e., obturator vessels and lymph node packet) are encountered medial and superior to the obturator nerve. After dissection of obturator lymph nodes, the external iliac lymph node packet is dissected. Hemo-lok clips are used to minimize the risk of lymphocele formation.

\section{Vesicourethral anastomosis}

Two 3/0 V-LocTM (Covidien, Mansfield, MA, USA) sutures are used for vesicourethral anastomosis. Running sutures start anteriorly at the 12 o'clock position on the $\mathrm{BN}$ from outside to inside, then from inside to outside on the urethra (Figure 4D). On either side, the anastomosis 
is completed by approximating the posterior aspect of the $\mathrm{BN}$ and urethra over an $18 \mathrm{Fr}$ catheter. After the bladder is irrigated to check the anastomosis for leaks, the robot is undocked and the wound is closed in layers.

\section{Discussion}

In this article we described our step-by-step techniques for single-port robotic-assisted extraperitoneal and perineal radical prostatectomy as recent technical advancements in this field. Since implementation of the da Vinci SP ${ }^{\circledR}$ platform at our institute, we have used the platform on over 100 upper and lower urinary tract procedures. There may be some intraoperative difficulties with singleport surgery in initial cases. However, with experience, potential advantages as a better cosmetic result as well as a quick recovery may outweigh these difficulties. Moreover, avoiding the peritoneal cavity can also be associated with a lower rate of bowel related complications such as ileus (11).

Transperineal and extraperitoneal approaches allow for minimal systemic $\mathrm{CO}_{2}$ absorption with potential advantages in patients with a limited pulmonary reserve (11). Bladder manipulation is minimized in these procedures potentially result in improved recovery of continence. Supine position may also reduce the adverse effects associated with steep Trendelenburg traditionally used in robotic-assisted radical prostatectomy $(18,19)$. Additionally, the platform is not bulky, the camera and working instruments are double-articulating and well-designed to access the target organ through a single incision. The physical characteristics of the da Vinci SP ${ }^{\circledR}$ make extraperitoneal and transperineal access to the prostate less challenging than conventional robotic systems.

At the time of this writing, we have done single-port radical prostatectomy with extraperitoneal approach on 60 patients with localized prostate cancer. Mean operative time was 198 minutes and no major perioperative complications occurred. Interestingly, with a median hospital stay of 4.2 hours, $73 \%$ of patients were discharged home on the day of surgery with minimum (if any) postoperative pain. Notably, only $10 \%$ of last 30 patients in this cohort received postoperative narcotics for pain control.

Regarding single-port perineal prostatectomy, since implementation of the da Vinci $\mathrm{SP}^{\circledR}$ at out institute, we have done 21 procedures. All of these patients had characteristics made them risky for transabdominal surgery (e.g., multiple previous surgeries, abdominal stoma, anorectal resection). With a median operative time of 262 minutes, patients were discharged home after a median hospital stay of 23.3 hours without any major postoperative complications.

Potential limitations associated with these techniques include no or limited long-term data regarding the oncological and functional outcomes at this time. The rate of symptomatic lymphocele may be higher when the peritoneum (as an absorbing surface) remains intact (20). The limited working space, learning curve as well as surgeon and bed-side assistant coordination may be challenging during the early learning curve. Multi-institutional collaborative training activities can be helpful in shortening the learning curve of these new procedures. Comparative trials with standard robotic surgery and cost-analysis studies remain hot topics for research after implementation of these new platforms in any institute.

\section{Acknowledgments}

Funding: None.

\section{Footnote}

Provenance and Peer Review: This article was commissioned by the Guest Editor (Ashok K. Hemal) for the series "Robotic-assisted Urologic Surgery" published in Translational Andrology and Urology. The article was sent for external peer review organized by the Guest Editor and the editorial office.

Conflicts of Interest: The series "Robotic-assisted Urologic Surgery" was commissioned by the editorial office without any funding or sponsorship. JK has a consultant agreement with Intuitive Surgical. The other authors have no other conflicts of interest to declare.

Ethical Statement: The authors are accountable for all aspects of the work in ensuring that questions related to the accuracy or integrity of any part of the work are appropriately investigated and resolved. The study was approved by Institutional Review Board (No. 13-780).

Open Access Statement: This is an Open Access article distributed in accordance with the Creative Commons Attribution-NonCommercial-NoDerivs 4.0 International License (CC BY-NC-ND 4.0), which permits the noncommercial replication and distribution of the article with the strict proviso that no changes or edits are made and the original work is properly cited (including links to both the formal publication through the relevant DOI and the 
license). See: https://creativecommons.org/licenses/by-nc$\mathrm{nd} / 4.0 /$.

\section{References}

1. Kaouk J, Garisto J, Bertolo R. Different approaches to the prostate: the upcoming role of a purpose-built single-port robotic system. Arab J Urol 2018;16:302-6.

2. Aminsharifi AR, Goshtasbi B, Afsar F. Laparoendoscopic single-site nephrectomy using standard laparoscopic instruments: our initial experience. Urol J 2012;9:657-61.

3. Tugcu V, Ilbey YO, Mutlu B, et al. Laparoendoscopic single-site surgery versus standard laparoscopic simple nephrectomy: a prospective randomized study. J Endourol 2010;24:1315-20.

4. McCrory B, Lowndes BR, Wirth LM, et al. Ergonomic evaluation of laparoendoscopic single-site surgery ports in a validated laparoscopic training model. Work 2012;41 Suppl 1:1884-90.

5. Ng CF, Teoh JY, Chiu PK, et al. Robot-assisted singleport radical prostatectomy: a phase 1 clinical study. Int J Urol 2019;26:878-83.

6. Kaouk J, Garisto J, Eltemamy M, et al. Step-by-step technique for single-port robot-assisted radical cystectomy and pelvic lymph nodes dissection using the da Vinci ${ }^{\circledR}$ SP ${ }^{\mathrm{TM}}$ surgical system. BJU Int 2019. [Epub ahead of print].

7. Kaouk J, Garisto J, Bertolo R. Robotic urologic surgical interventions performed with the single port dedicated platform: first clinical investigation. Eur Urol 2019;75:684-91.

8. Kaouk J, Bertolo R, Eltemamy M, et al. Single-port robotassisted radical prostatectomy: first clinical experience using the SP surgical system. Urology 2019;124:309.

9. Janetschek G. Robotics: will they give a new kick to singlesite surgery? Eur Urol 2014;66:1044-5.

10. Bertolo R, Garisto J, Gettman M, et al. Novel system for robotic single-port surgery: feasibility and state of the art in urology. Eur Urol Focus 2018;4:669-73.

Cite this article as: Aminsharifi A, Sawczyn G, Wilson CA, Garisto J, Kaouk J. Technical advancements in robotic prostatectomy: single-port extraperitoneal roboticassisted radical prostatectomy and single-port transperineal robotic-assisted radical prostatectomy. Transl Androl Urol 2020;9(2):848-855. doi: 10.21037/tau.2019.11.35
11. Kallidonis P, Rai BP, Qazi H, et al. Critical appraisal of literature comparing minimally invasive extraperitoneal and transperitoneal radical prostatectomy: a systematic review and meta-analysis. Arab J Urol 2017;15:267-79.

12. Sujata N, Tobin R, Tamhankar A, et al. A randomised trial to compare the increase in intracranial pressure as correlated with the optic nerve sheath diameter during propofol versus sevoflurane-maintained anesthesia in robot-assisted laparoscopic pelvic surgery. J Robot Surg 2019;13:267-73.

13. Keller H, Lehmann J, Beier J. Radical perineal prostatectomy and simultaneous extended pelvic lymph node dissection via the same incision. Eur Urol 2007;52:384-8.

14. Saito S, Murakami G. Radical perineal prostatectomy: a novel approach for lymphadenectomy from perineal incision. J Urol 2003;170:1298-300.

15. Kaouk JH, Akca O, Zargar H, et al. Descriptive technique and initial results for robotic radical perineal prostatectomy. Urology 2016;94:129-38.

16. Ramirez D, Maurice MJ, Kaouk JH. Robotic perineal radical prostatectomy and pelvic lymph node dissection using a purpose-built single-port robotic platform. BJU Int 2016;118:829-33.

17. Bertolo RG, Garisto J, Eltemamy M, et al. Pure single-site trans-perineal robotic radical prostatectomy: first clinical report using the $\mathrm{SP} \circledast$ surgical system. Eur Urol Suppl 2019;18:e2282.

18. Hsu RL, Kaye AD, Urman RD. Anesthetic challenges in robotic-assisted urologic surgery. Rev Urol 2013;15:178-84.

19. Cockcroft JO, Berry CB, McGrath JS, et al. Anesthesia for major urologic surgery. Anesthesiol Clin 2015;33:165-72.

20. Stolzenburg JU, Wasserscheid J, Rabenalt R, et al. Reduction in incidence of lymphocele following extraperitoneal radical prostatectomy and pelvic lymph node dissection by bilateral peritoneal fenestration. World J Urol 2008;26:581-6. 